\title{
IMPLEMENTATION OF TECHNOLOGIES IN THE PUBLIC SERVICE: GEOMATICS IN THE CLOUD FOR MONITORING WETLANDS IN PROTECTED AREAS
}

\author{
I. Díaz-Hormazábal ${ }^{1 *}$, D. Valencia ${ }^{1}$, J. Valenzuela $^{2}$ \\ ${ }^{1}$ Sección de Monitoreo e Información del SNASPE, Gerencia de Áreas Silvestres Protegidas, Corporación Nacional Forestal, Chile. \\ Paseo Bulnes 259, Santiago, Chile. - diego.valencia@conaf.cl - ignacio.diaz@conaf.cl \\ ${ }^{2}$ Sección de Monitoreo e Información del SNASPE, región de Tarapacá, Corporación Nacional Forestal, Chile. Diagonal Francisco \\ Bilbao 3692, Iquique, Chile. - jorge.valenzuela@conaf.cl
}

KEY WORDS: cloud computing, google earth engine, hydroperiod, conservation, wetlands, protected areas.

\begin{abstract}
Wetlands protection has been a constitutive part of the conservation strategies that the Chilean Forest Service has implemented in the Protected Wild Areas of Chile. These ecosystems are highly vulnerable to changes in their hydrological regime, generating direct effects on the biodiversity associated with them. These changes may be related to the rainfall regime, however, the activities of drainage, overgrazing, landfill, or tributary deviation are the greatest threats that these ecosystems face today. For years, long-term satellite information was dismissed in the Chilean public service due to the lack of technical, computational or software capabilities. Nowadays, cloud computing tools with massive geodata analysis have democratized remote sensing, giving way to the development of web applications and online information analysis platforms. An interactive web application was developed in Google Earth Engine (GEE) that uses spectral indexes correlated with the presence of water, generating estimates in "almost real time" on Landsat and Sentinel-2 images. The Surface Water Satellite Monitoring Platform allows the automatic processing through the internet of the images available for the analyzed wetlands, overcoming the time and computational capacity restrictions required with conventional geomatics programs. This has allowed to support the management of these ecosystems, reducing the costs of field work and increasing the efficiency in the monitoring of wetlands in the Protected Wild Areas of Chile.
\end{abstract}

\section{INTRODUCTION}

Wetlands offer a wide variety of ecosystem services and provide habitat for many species of high ecological value (Ahumada et al. 2011). These ecosystems are highly vulnerable and susceptible to changes in the water supply, since alterations and modifications in the hydrological regime have direct effects on the ecophysiological condition and the vegetation cover of the wetland. Its high fragility may be associated with natural causes, such as changes in the rainfall regime, however, anthropic causes, such as drainage activities, excessive grazing, landfill, or alteration in the water regime, these are the greatest threats these ecosystems face today (CONAF-UCh, 2016). That is why its management has been a constitutive part of the conservation strategies that the Chilean Forest Service has implemented in the National System of Protected Areas of the State (SNASPE).

To better understand its operation, as well as for the planning of its conservation, it is of vital importance to maintain an effective and cost-effective monitoring that allows keeping a historical and real-time record of the changes that may occur in the short and long term (Araya-López et al. 2018). Even so, the monitoring of wetlands is still a challenge, since they can be highly fluctuating ecosystems in the extension of their surface water, so we can find wetlands with permanent waters throughout the year, to lands that remain dry for several months (Muro et al. 2016). Understanding this dynamic is very important for the maintenance of the structure and functioning of the ecosystem, since it is the main physical, chemical and biotic regulator of these ecosystems. (Babbitt, 2005). This requires satellite sensors that allow a monthly or a couple of days periodic monitoring, which is possible today thanks to the Sentinel-2 sensor. Furthermore, depending on the water surface; depth, physicochemical characteristics of water, shadows, among others, it is necessary to make a specific adjustment for each wetland to achieve good results. The use of spectral indexes correlated with the presence of water, allow surface estimates using optimized thresholds, providing a useful way for their study, however, it is necessary to use mass image processing algorithms in order to reconstruct and understand their hydroperiod or temporal variability. In this sense, today the tools of "Cloud Computing" such as Google Earth Engine (GEE), have managed to overcome a series of inconveniences of time and computing capabilities that facilitate the processing and analysis of large amounts of satellite images. Thus, as in 2017, the SNASPE Monitoring and Information Section has begun to generate a series of tools in the GEE platform, which aim to support decision-making and management in SNASPE, using standard and scalable methodologies at the level of the entire protected areas system.

The present work, focused on monitoring changes in surface water extension of protected wetlands in the SNASPE in the north and center of the country, makes use of these geomatic tools with cloud computing technology and free access, to respond to the current state and historical behavior of surface water in protected wetlands.. The results were reflected in the development of an online platform that will allow in "almost real" time monitoring of the changes in the extension of the lagoon, automatically incorporating the new images that are being captured by the Landsat- 8 and Sentinel- 2 sensors.

\section{MATERIAL AND METHODS}

\subsection{Data source}

The satellite images used were consulted and analyzed directly on the GEE online platform. The images of the Landsat-5 (TM), Landsat-7 (ETM +) and Landsat-8 (OLI) programs of the United States Geological Survey (USGS) were used, in addition to the Sentinel-2 program of the European Space Agency (ESA). While surface water movement can be very fast, changing dramatically between Landsat image acquisitions (every 16 days), this sensor represents an important long-term multitemporal reference for water monitoring (1985 to present), which was complemented with greater temporal and spatial resolution through the Sentinel-2 project available since 2015. 
In all products used, radiometric measurements of each pixel are provided in the surface reflectivity. This allows to incorporate the necessary corrections to reduce the inter-image variability due to atmospheric effects that could alter the multitemporal analysis of the spectral index. The Landsat product observations record should be considered to have some uncertainty during the period prior to 1999 , due to the commercial management of the Landsat program between 1985 and the early 1990's, where coverage was often limited to the line of sight of the receiving stations and complete global coverage was not provided, so geographical and temporal inequalities are particularly evident until 1999 (Pekel et al. 2016). Likewise, there is an absence of data in 2012, a period of lag between the end of the Landsat 5 mission and the launch of Landsat 8 .

\subsection{Spectral indexes}

Several studies have classified water on satellite images, often using the McFeeters (1996) NDWI standardized water difference index or Xu's NDWI (2006). These indices are relatively easy to calculate, since they only use two input bands, the green color band and the near infrared (NIR) and shortwave infrared (SWIR) bands, respectively. However, there are more complex indices such as the Danaher \& Collett (2006) WI that combines five bands, and the Feyisa et al. (2014) that proposed shadowless water detection indexes (AWEI nsh) and with shadows of mountains or clouds (AWEI sh), which use four and five bands respectively. All the indexes described above allow water pixels to be classified by applying a threshold, which can be adjusted for different images or for different classification priorities, depending on the characteristics of the surface water; depth, physicochemical characteristics of water, shadows, among others.

\subsection{Calibration and threshold adjustment}

The calibration process has been carried out gradually generating pilot initiatives at regional level. This is how during the year 2018 and 2019 photogrammetric flights were carried out through RPA (Remotely Piloted Aircraft) of two wetlands (Arabilla and Parincota), inserted in the Isluga Volcano National Park of Tarapacá region, which allowed adjusting the estimates of the Surface Water Satellite Monitoring Platform (Spanish acronym, Plataforma de Monitoreo Satelital de Espejos de Agua; PMSEA) locally. By incorporating a regional monitoring program, RPA flights were generated in accordance with the passage of Landsat 8 and Sentinel-2 satellites. In this way the generated images allowed to adjust the detection threshold of these two surface water. In addition to the above, for these two lagoons a comparison was also made with historical images of Google Earth (year 2003 onwards). The images were selected according to their quality and temporal proximity with some satellite scene. Subsequently, they were georeferenced and corregistered to match spatially with satellite images. The measurement of the surface of the lagoon in these images was estimated by manual digitization of polygons around the water body. An object-based accuracy assessment was done by comparing manually delineated wetlands (using Google Earth imagery) and water index polygons. Since the spatial resolution of Google Earth imagery allows a better detailed delineation of wetlands than the Landsat spatial resolution $(30 \mathrm{~m})$ or Sentinel-2 $(10 \mathrm{~m})$, we resampled the Google Earth-delineated polygons to satellite imagery resolution prior to calculating the delineation errors. A total delineation error (ranging from 0 to 1 ) was calculated, which accounts for both overestimated and underestimated area (Ardila et al. 2012).
Finally, comparisons were also made with the GSW product or Global Surface Water Mapping Layers, generated by the Joint Research Center of the European Commission, which contains monthly maps of the location and temporal distribution of surface waters of much of the world from 1984 to 2015 . The surface water identification in this product uses images derived from Landsat TM, ETM + and OLI satellite for a resolution of 30 meters. This product, embodied in the manuscript of Pekel et al. 2016, was widely validated using globally and temporarily distributed control points throughout the 32 years analyzed. This allows us to have a reliable reference as a point of comparison of past data obtained through spectral indexes in the PMSEA. In this way, various combinations of spectral and threshold indices were tested, which were graphically compared by time series with the GSW product.

\subsection{Platform construction}

Through the GEE JavaScript API, an interactive tool was built that allows you to select between ten wetlands contained in four SNASPE units. Once the wetland is selected, must choose between the five spectral indexes mentioned above, and then adjust the detection threshold. The schematic flow of the platform is shown in figure 1 .

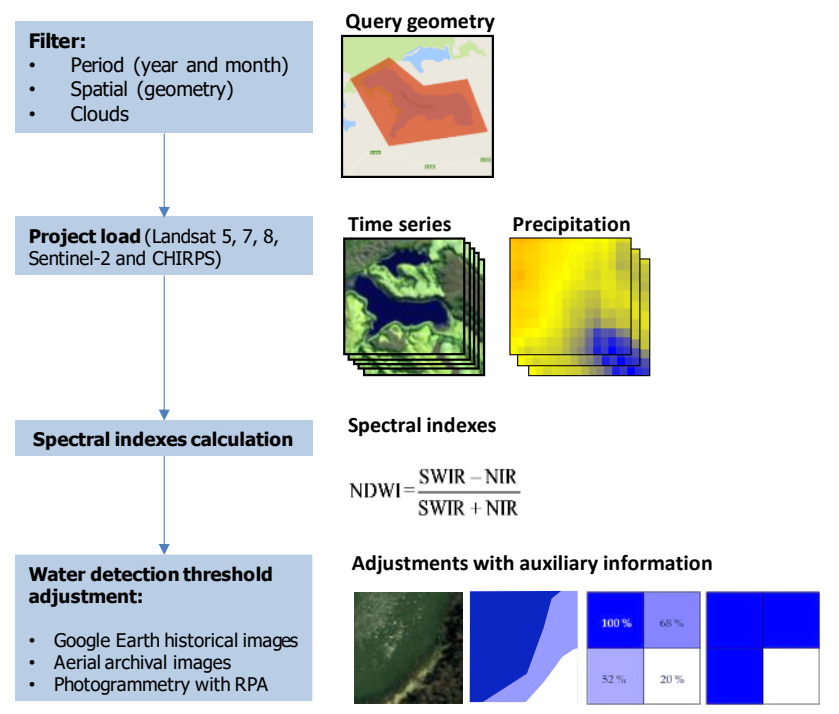

Figure 1. Methodological scheme of surface water detection using spectral indexes.

\section{RESULTS}

\subsection{Platform}

The platform consists of two panels, the panel on the right side through a drop-down menu allows you to choose the SNASPE unit of interest and then the lagoon to be consulted, this generates the time series graph of the estimated surface of the surface water since 1985 to the present (Figure 2). Additionally, this panel shows a bar chart of the annual accumulated rainfall for the same period. This information is calculated based on the precipitation dropped on the basin that directly supplies the lagoon, which is derived from the data of CHIRPS v.2. product of the Climate Hazards Group (CHG), global rainfall data set, with historical records of more than 30 years, combining information from estimates derived from satellites and rainfall stations (Funk et al. 2014). On the other hand, the left panel is a Google Maps browser where the view is automatically focused on the lagoon consulted, and you can choose to view thematic 
or satellite cartography. In addition, GEE's online Integrated Development Environment (IDE) delivers interactivity to time series graphs, since when passing over some point of the series, the date of the image is shown, and when clicking on a particular point, the corresponding image will be displayed on the left panel along with the surface water detection vector. This allows us to review the behavior of the spatial distribution of the lagoon image by image throughout the period (Figure 2). The platform also allows to expand the figures and download the graphics and data to be analyzed later.

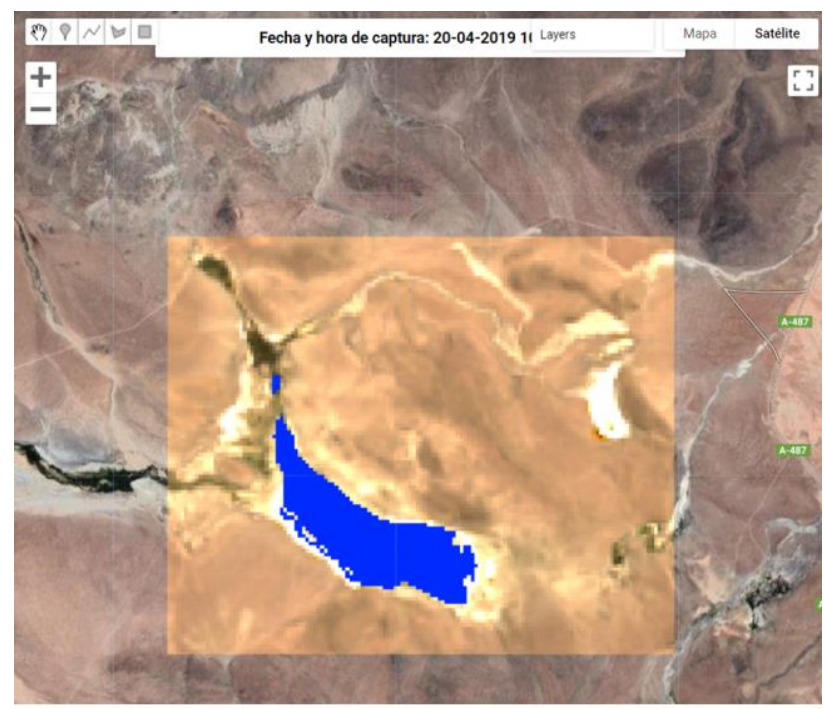

PLATAFORMA DE MONITOREO SATELITAL DE ESPEJOS DE AGUA (PMSEA) DEL SISTEMA NACIONAL DE ÁREAS SILVESTRES PROTEGIDAS DEL ESTADO (SNASPE)
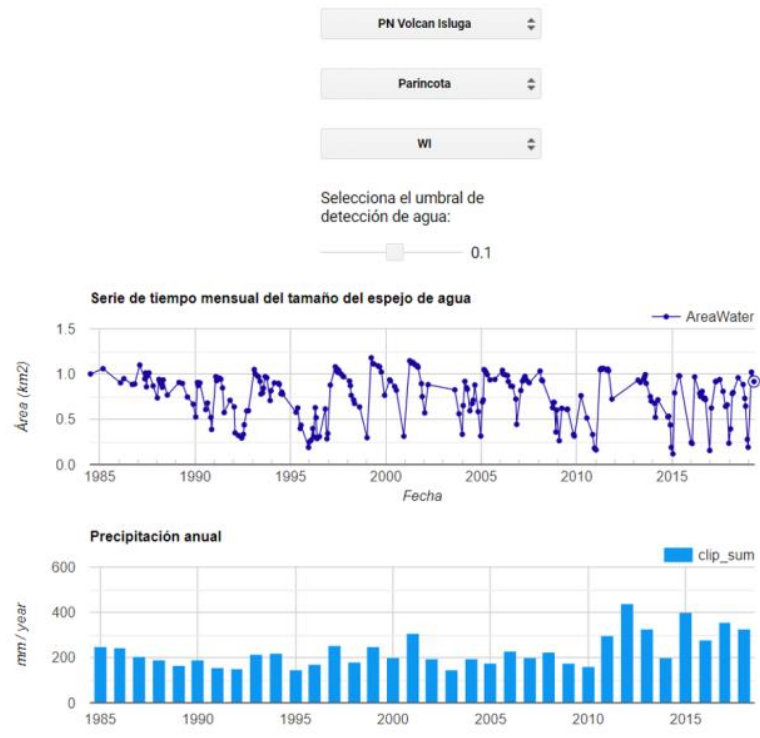

Figure 2. Surface Water Satellite Monitoring Platform of SNASPE.

\subsection{Calibration and threshold adjustment}

Through the photogrammetric flights, the entire length of the Arabilla and Parincota surface water was covered. High precision mosaics of the lagoons were constructed with a resolution of $5.5 \mathrm{~cm} /$ pixel and a horizontal precision error that varied between 0.8 and $1.3 \mathrm{~cm} / \mathrm{pixel}$. This product allowed to estimate the extension of the surface water with greater accuracy by manually digitizing polygons around the surface water, to later adjust the spectral indexes to the edge of the lagoon (Figure 3).
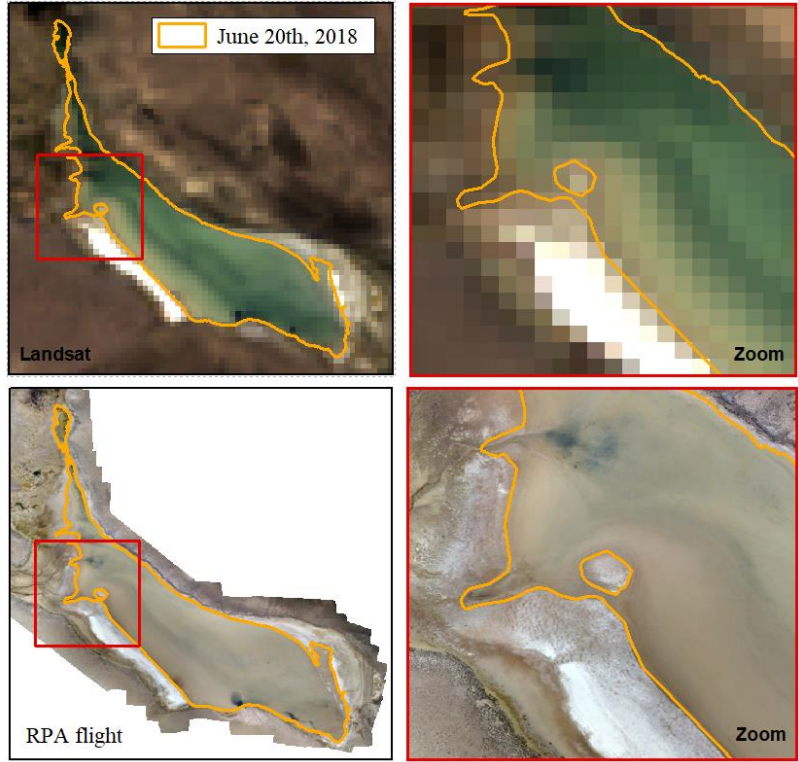

Figure 3. Parincota wetland, Isluga Volcano National Park. Adjustment of the detection threshold for estimating the extension of the surface water.

Comparisons were made between the spectral indexes and a series of 30 historical images extracted from Google Earth. The object-based accuracy assessment showed a mean delineation agreement of 0.81 (standard deviation of 0.1 ) between the Satellite water index polygons and the manually delineated wetlands using Google Earth imagery. The most important differences were observed with Landsat images in summer when the size of the lagoon is small and 30 meter pixels underestimate the actual extension. In all these images the lagoon boundaries were manually digitized, to then compare the calculated surfaces with those estimated by satellite information. In this way, it was observed that a large part of the auxiliary information confirms the variability pattern of the lagoons studied, both for summer minimums and winter maximums (Figure 4).

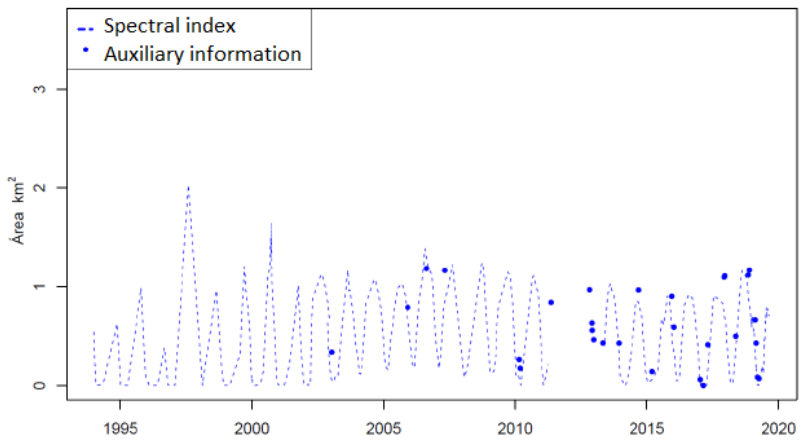

Figure 4. Wetland, Isluga Volcano National Park. Comparison of the monthly series calculated with spectral index and auxiliary information.

On the other hand, the comparison with the GSW product shows that the majority of the indexes behaved stably among them and also maintain the pattern of variability observed in the GSW product (Figure 5). Although there are some differences 
in the range of surfaces covered by the indexes, in general, most of them have a homogeneous behavior from 1997 onwards, before this date, there is a smaller amount of images available, which dramatically increases the deviation from the average. In general, Fisher's Wi index (2016) is the closest to the GSW reference curve (Figure 5).

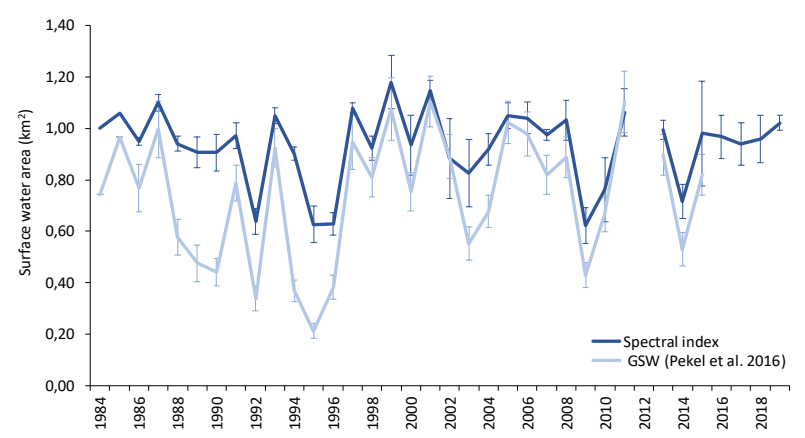

Figure 5. Parincota wetland, Isluga Volcano National Park. Comparison of the calculated annual series between the spectral indexes and the GSW product.

\section{DISCUSSION}

Of the analyzed wetlands, the surface waters of the north and central part of the country have an important monthly and annual variability in their extension, being able to fluctuate between $20 \%$ and $40 \%$ less with respect to the maximum of the analyzed period, such as Arica and Parinacota, Tarapacá and Valparaíso regions. This variability is evident mainly due to the smaller size and depth of the surface water in the northern zone (Figure 6). The incorporation of Sentinel-2 allows capture such variability, although it remains a challenge especially for shortterm events, due to satellite observation and cloud-free coverage must be simultaneous with the occurrence in variability (Pekel et al. 2016).

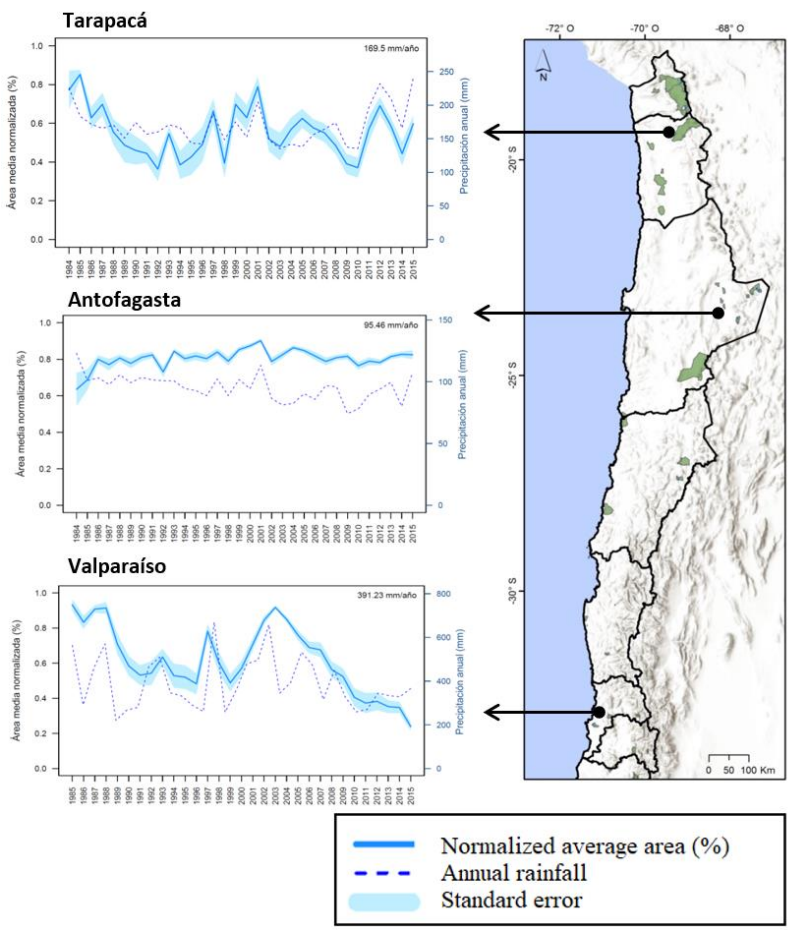

Figure 6. Time series of water surface changes for SNASPE wetlands in the north and central part of Chile.

The historical results generated with PMSEA have made evident the drought problems that exist in the country. Although rainfall has increased in recent years in the northern part of the country (Figure 6), the rainfall deficit has remained uninterrupted since 2010 to date, which keeps dropping water reservoir levels (CR2, 2017). From 2010 to the present there has been an uninterrupted sequence of dry years, an event called "The mega-drought" (Garreaud et al. 2017), where the amount of water flowing in the rivers of central Chile has been reduced in direct response to the rainfall deficit during this period, whose effect is also evident in lakes, reservoirs, snow and groundwater (CR2, 2015).

It can be seen in the figures of temporal tendency (Figure 5) that precipitation is a co-variable that can explain quite well the changes in the surface of water bodies in the north and center of the country. So, this relationship allows to demonstrate anomalous behaviors in the natural fluctuation of the extension of the water bodies. In this way, the monitoring tool developed, has allowed to identify extreme cases where the water resource has decreased considerably with respect to its historical behavior, even in some cases in the central zone of the country, the dynamics of the hydroperiod due to drought have moved from an annual flooding regime to a seasonal one, emptying almost completely in the summer.

\section{CONCLUSION}

The Surface Water Satellite Monitoring Platform (PMSEA) has allowed to know both monthly and annual fluctuation in the extension of surface water of wetlands within the SNASPE of the northern and central zone, as well as defining the ranges in which these ecosystems naturally vary over a period of approximately 30 years. Knowing this information allows thresholds and alerts to be established, which facilitate management decisions in time to act in the face of degradation processes or other threats.

Undoubtedly, remote sensing has provided a useful way to study changes in wetlands through spatially explicit data. However, the arrival of geomatic tools with cloud processing has facilitated the development of platforms that support the implementation and maintenance over time of an efficient cost and democratic satellite monitoring.

\section{ACKNOWLEDGEMENTS}

Acknowledgments to financial support of the National Integrated System for Forest Ecosystem Monitoring and Evaluation (SIMEF) and Romina Novoa-Melson Project for the translation and comments on the manuscript.

\section{REFERENCES}

Ahumada, M., Aguirre, F., Contreras, M., Figueroa, A. 2011. Guía para la Conservación y Seguimiento Ambiental de Humedales Andinos. Ministerio de Medio Ambiente, SAG, DGA, Chile.

Araya-López, R., Lopatín, J., Fassnacht, F., Hernández, J. 2018. Monitoring Andean high altitude wetlands in central Chile with seasonal optical data: A comparison between Worldview-2 and Sentinel-2 imagery. ISPRS J. Photogrammetry and Remote Sensing, 145, 213-224. 
Ardila, J.P., Bijker, W., Tolpekin, V.A., Stein, A. 2012. Context-sensitive extraction of tree crown objects in urban areas using VHR satellite images. International Journal of Applied Earth Observation and Geoinformation. 15, 57-69.

Babbitt, K. J. 2005. The relative importance of wetland size and hydroperiod for amphibians in southern New Hampshire, USA. Wetlands Ecology and Management, 13(3), 269-279. https://doi.org/10.1007/s11273-004-7521-x

CONAF - Universidad de Chile. 2016. Manual para el establecimiento de programas de monitoreo en humedales insertos en el Sistema Nacional de Áreas Silvestres Protegidas del Estado de Chile. Santiago, Chile. 134 p.

CR2. 2015. Report to the Nation: The Central Chile MegaDrought. Technical report from the Center for Climate and Resilience Research. 30 pp. Santiago-Chile. Available on line at: http://www.cr2.cl/megasequia

CR2. 2017. De la Mega a la Mediasequía, por René Garreaud. Nota de prensa revisada el 29 de noviembre de 2017. Available on line at: http://www.cr2.cl/de-la-megasequia-ala-mediasequia-por-rene-garreaud

Danaher, T., Collett, L. 2006. Development, optimisation and multi-temporal applica- tion of a simple Landsat based water index. The 13th Australasian Remote Sensing and Photogrammetry Conference. Canberra.

Feyisa, G.L., Meilby, H., Fensholt, R., Proud, S.R. 2014. Automated Water Extraction Index: A new technique for surface water mapping using Landsat imagery. Remote Sensing of Environment, 140,23-35. doi:10.1016/j.rse.2013.08.029.

Fisher, A., Flood, N., Danaher, T., 2016. Comparing Landsat water index methods for automated water classification in eastern Australia. Remote Sensing of Environment 175, 167-182. doi:10.1016/j.rse.2015.12.055

Funk, C.C., Peterson, P.J., Landsfeld, M.F., Pedreros, D.H., Verdin, J.P., Rowland, J.D., Romero, B.E., Husak, G.J., Michaelsen, J.C., Verdin, A.P. 2014. A quasi-global precipitation time series for drought monitoring: U.S. Geological Survey Data Series 832, 4 p., doi:10.3133/ds832

Garreaud, R., Alvarez-Garreton, C., Barichivich, J., Boisier, J.P., Christie, D., Galleguillos, M., LeQuesne, C., McPhee, J., Zambrano-Bigiarini, M. 2017. The 2010-2015 mega drought in Central Chile: Impacts on regional hydroclimate and vegetation. Hydrology and Earth System Sciences Discussions. 1-37. doi:10.5194/hess-2017-191

McFeeters, S.K. 1996. The use of the Normalized DifferenceWater Index (NDWI) in the delineation of open water features. International Journal of Remote Sensing, 17, 1425-1432. ttp://dx.doi.org/10.1080/01431169608948714.

Muro, J., Canty, M., Conradsen, K., Hüttich, C., Nielsen, A., Skriver, H., Remy, F., Strauch,A., Thonfeld, F., Menz, G., 2016. Short-Term Change Detection in Wetlands Using Sentinel-1 Time Series. Remote Sensing. 8, 795. doi: $10.3390 /$ rs 8100795

Pekel, J.F., Cottam, A., Gorelick, N., Belward, A.S. 2016. Highresolution mapping of global surface water and its longterm changes. Nature, 540, 418-422. doi: 10.1038 /nature20584.

$\mathrm{Xu}, \mathrm{H}$. 2006. Modification of normalised difference water index (NDWI) to enhance open wáter features in remotely sensed imagery. International Journal of Remote Sensing, 27,3025-3033.

http://dx.doi.org/10.1080/01431160600589179. 